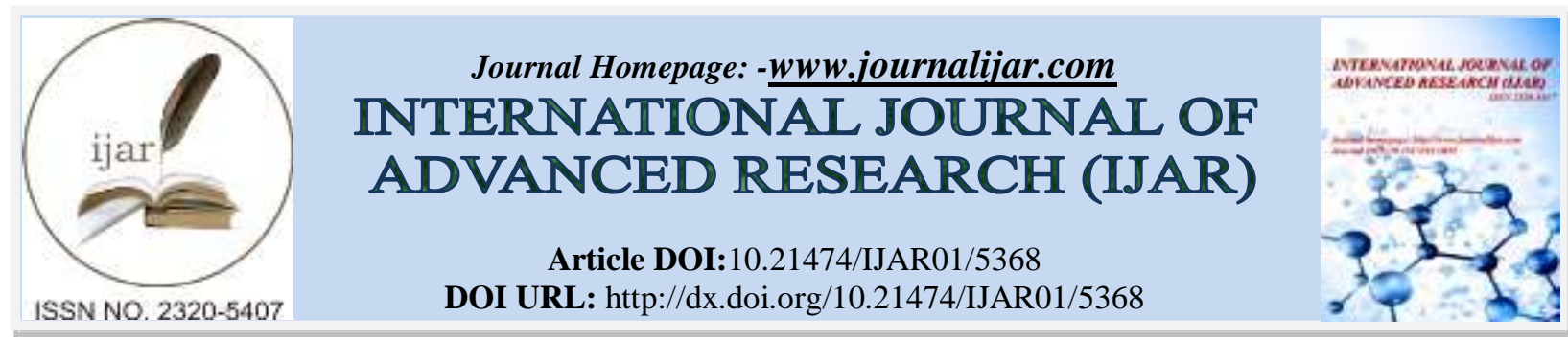

RESEARCH ARTICLE

\title{
OUTBREAK OF SCRUB TYPHUS IN PYREXIA OF UNKNOWN ORIGIN DURING COOLER MONTHS IN GUNTUR DISTRICT, ANDHRA PRADESH, SOUTH INDIA.
}

\author{
Dr. Y. Umarani, " Dr. D. Sarada, Dr. Jyothi P, Dr. E. Vandana, Dr. R. Suma Kalyani and Dr. M. \\ Rajarajeswari.
}

Assistant Professor, Department of Microbiology, Siddhartha Medical College, Vijayawada, Andhra Pradesh.

\section{Manuscript Info}

Manuscript History

Received: 09 July 2017

Final Accepted: 11 August 2017

Published: September 2017

Key words:-

Scrub typhus,

Orientia tsutsugamushi, Weil-Felix test, Immunochromatographic assay, ELISA,

Pyrexia of Unknown Origin.

\begin{abstract}
Scrub typhus is a Rickettsial infection caused by Orientia tsutsugamushi and transmitted by bite of the chigger of a mite Trombidium deliense. It is an acute febrile illness and Zoonotic disease endemic in the South East Asian countries and Western pacific region but less common known cause of PUO in India. Treatment is simple with Doxycycline and Azithromycin being drugs of choice and delay in diagnosis can be fatal. A total of 216 patients attending Medical OP with PUO at GGH, Guntur, from September 2013 to February 2014 were considered for the study. Suspected cases with Eschar (58) were screened for IgM antibodies to Orientia tsutsugamushi by Weil-Felix and Rapid Immunochromatographic method and positive for either of these tests were further confirmed by ELISA. They were also screened for Malaria, Typhoid, Tuberculosis, HIV and Hepatitis B infections. Scrub typhus IgM antibodies were positive in 26(44.8\%) by both WeilFelix and ELISA, 56(96.5\%) cases were positive and 2 negative with Immunochromatographic assay and $57(98.3 \%)$ were positive with ELISA. Among 58 screened positive cases, 36(62.69\%) were males and $22(37.9 \%)$ females. Scrub typhus positivity was higher in males than females. The lesion eschar was present in 56(96.5\%) cases. The laboratory parameters were abnormal in most of the patients as evident by thrombocytopenia $(82.7 \%)$, deranged liver functions $72.4 \%$ and renal functions $24.1 \%$. Scrub typhus is prevalent but an under diagnosed disease in India and early diagnosis and administration of antibiotics will prevent the complications and mortality.
\end{abstract}

Copy Right, IJAR, 2017,. All rights reserved.

\section{Introduction:-}

Scrub typhus is an acute febrile illness caused by Orientia tsutsugamushi which is a gram negative obligate intracellular bacteria transmitted by the bite of infected larva (chigger) of a mite Leptotrombidium deliense in India. Scrub typhus is a zoonotic disease in which humans are the accidental hosts. Scrub typhus or bush typhus is named from the type of vegetation that harbors the vector Leptotrombidium deliense i.e., secondary vegetation in transitional terrain between woods and clearings. Scrub typhus is an important military disease and thousands of cases occurred during the Second World War.

Corresponding Author:-D. Sarada.

Address:-Assistant Professor, Department of Microbiology, Siddhartha Medical College, Vijayawada, 
PUO can be defined as temperature above $38.3^{\circ} \mathrm{C}$ for more than one week duration and there are multiple causes like Malaria, Dengue, Flu, Enteric fever and Tuberculosis. Scrub typhus is a very less known cause of PUO always under diagnosed in India due to its non specific clinical presentations, low level of suspicion amongst clinicians, lack of awareness and limited diagnostic facilities. The disease is endemic in East Asia from Korea to Indonesia and in Pacific Islands including Australia and was first observed in Japan.

An outbreak of PUO was observed in Guntur district, Andhra Pradesh during cooler months from September 2013 to February 2014. A total of 216 cases were recorded in medical OP at GGH, Guntur. Only suspected cases of PUO with presence of characterstic eschar were tested for IgM antibodies by Weil-Felix and rapid ICT test. The positive tests were further confirmed by IgM ELISA. The present study was undertaken to estimate the prevalence of the disease in clinically suspected patients to compare rapid ICT which is simple and IgM ELISA method. There was 96.5\% and $98.3 \%$ positivity in rapid ICT and ELISA respectively than Weil-Felix test which is neither sensitive nor specific for diagnosis of these diseases.

\section{Materials And Methods:-}

A total of 216 patients attended the medical OP in GGH Guntur with PUO from September 2013 to February 2014 and a number of 58 suspected cases were screened for scrub typhus by Weil-Felix agglutination test containing Proteus vulgaris antigen suspension OX19, OX2 and Proteus mirabilis antigen suspension OXK(Tulip diagnostic Pvt Ltd Goa, India) and Rapid Immunochromatographic assay or ICT (standard diagnostics, Bioline, Inc, Korea) containing a major surface protein $56 \mathrm{KDa}$ antigen representative of Orientia tsutsugamushi (Karp, Kato, Gilliam). Weil-Felix test with a titre of $>1: 160$ and ICT positive were considered positive. All 58 positive for IgM antibodies of scrub typhus were further confirmed by IgM ELISA (Bio International seatle, WA, USA) that used recombinant antigens to detect IgM antibodies for $\mathrm{O}$ tsutsugamushi.

The data was statistically analysed on SPSS 17.0 software by using chi-square (x2) test. The probability value (P value) was calculated and P-value of less than 0.00001 was considered significant.

\section{Results:-}

A total of 216 patients with PUO reported to Medical OP, GGH, Guntur from September 2013 to February 2014. Among 216, only suspected cases with fever $>38.3^{\circ} \mathrm{C}$ for more than one week with eschar were screened for IgM antibodies for Scrub typhus and 58 cases were Seropositive. More number of cases were reported in the months of September and October in 2013(Figure1).

Among these 58 positive cases 36(62.9\%) were male and 22(37.9\%) were female. Males were more affected than females. Age-wise and sex-wise distribution and their seropositivity are shown in figure2. Age group of the patients ranged between 2 to 80 years. The seropositivity for IgM antibodies was highest in 41-60 yrs (56.8\%) age group followed by $21-40 y r s(32.7 \%)$ in both sexes.

Weil-Felix test was positive in 26 cases (44.8\%) and negative in 32(55.1\%). Rapid Immunochromatographic assay (Fig. III) positive in 56(96.5\%) and negative in two cases (3.5\%). ELISA was positive in 57(98.3\%) and negative in one patient (1.07\%). The correlation between rapid ICT and ELISA was 96.5\% and 98.3\% respectively (Table I).

Fever $>38.3^{\circ} \mathrm{C}$ for one week with chills and rigors was the most common manifestation (100\%) including nausea and vomiting. Presence of characteristic eschar was observed in $56(96.5 \%)$ patients. Other presentations like Hypotension, Myalgia (86.2\%), Hepatosplenomegaly (62\%), Abdominal pain 34\%, Cough with dyspnoea 25.8\%, Oliguria $34.4 \%$ and Skin rash in $5(8.6 \%)$ patients. There was no eschar in 2 patients. Among these 58 cases, $1(1.7 \%)$ death was reported due to Acute respiratory failure (Table II).

The laboratory parameters thrombocytopenia, deranged liver function tests and renal function tests were seen in 48(82.7\%), 42(72.4\%) and 14(24.1\%). Total Leucocyte count was raised in 44(75.8\%) (Table III). Most of the patients were from rural areas belonging to Guntur, Prakasam and Krishna districts of Andhra Pradesh. Number of cases reported during cooler months between September and October were high. All 58 cases were negative for common causes of fever such as typhoid, tuberculosis, malaria, dengue, HIV and Hepatitis B. All cases diagnosed as scrub typhus were followed up and one death was reported and it was not significant. 


\section{Discussion:-}

Rickettsial infections are reemerging with increasing reports from India and other countries with considerable morbidity and mortality. Scrub typhus is a rickettsial infection caused by Orientia tsutsugamushi. Incidence of scrub typhus varies from $0.8 \%$ to $60 \%$ in different countries.

Among 216 recorded cases with PUO, a total of 58 cases reported with fever $>38.3^{\circ} \mathrm{C}$ with chills and rigors, were tested for the presence of antibodies and were found to be positive. Among these 36 were males and 22 were females. Incidence was more among males than females and this correlates with studies by $\mathrm{S}$ Gurung et al. who reported 204 patients with PUO and 63 were confirmed positive of which 42 were males and 21 females, A Ramyasree et al. tested 100 patients among which 39 were positive and of these 23 were males and 16 were females. Highest seropositivity was observed in 41-60years age group which correlates with the study of A Ramyasree et al. and R Bithu et al.

The prevalence of Fever with chills and rigors with vomiting (100\%) and presence of characteristic eschar (96.5\%) were the most common presentations in our study which is similar to a study by S Gurung et al., A Ramyasree et al. and others. S Gurung et al. have reported eschar in 12 patients and studies in Korea reported a high incidence of eschar. This may be due to variation in serotypes among the regions and also the eschar is usually painless and does not itch, so remains undetected.

In the present study most of the patients were from rural background. The number of cases reported in the months of September and October were high. This is because of the increased activity of mites during or at the end of rainy season (Figure I) which correlates with study by R Bithu et al., Sharma A et al. and Vivekanandan M et al.

Several studies have reported eschar and skin rash in different populations from different parts of the world. The prevalence of the rash has been reported varying from $8.9 \%$ to $90 \%$ by different authors and in our study, it was 8.6\%. S Gurung et al. reported eschar in 12 cases and rash in 14(34.4\%). Hypotension (86.2\%) was another abnormal parameter in our study and Vivekanandan M reported $16 \%$ incidence in his study. The most important abnormal laboratory parameter noticed in the present study was thrombocytopenia 48(82.7\%). Other laboratory findings include elevation of liver enzymes, serum urea and serum creatinine. Similar abnormalities have been observed by R Bithu et al. and Vivekanandan $\mathrm{M}$ et al. and other studies.

In this study, one death $1.7 \%$ has been reported due to acute respiratory failure with fever, cough and dyspnoea. R. Bithu et al. reported a mortality of $9.7 \%$ in their study of 133 cases with common cause of death as acute respiratory failure presenting with fever, cough and dyspnoea.

The diagnosis of scrub typhus is a problem due to low index of suspicion and lack of diagnostic facilities in India. Weil-Felix test is widely used in diagnosis of rickettsial diseases but this test is neither sensitive nor specific. The test result may be negative during early stages of disease, the antibodies are detectable only during second week of the onset of the disease. It has been replaced by more accurate and sensitive immunological tests. Among these, specific immunological tests, indirect immunofluorescence test and PCR which provide accurate and specific diagnosis, either not available or are too expensive. There is need for a rapid technically simple and economic test. ELISA is an easy and comparatively economic test. In the present study suspected cases (58) were screened with W-F test and rapid immunochromatographic assay and positive cases were further confirmed by IgM ELISA. Gurung et al., reported positive test with W-F 51, ICT in 64 and IgM ELISA in 63 patients. In our study 2 samples were negative by rapid method but positive by ELISA and one sample positive by rapid method (ICT) was negative for ELISA which correlated with the study of Gurung et al., with one patient's sample positive for Weil-Felix and ICT and negative for IgM ELISA. By using rapid test and ELISA for detection of antibodies of scrub typhus the positivity was $96.5 \%$ and $98.2 \%$ in our study. The difference was statistically significant. Sharma et al. tested 150 samples from patients with PUO of which 52 were found to be positive for OXK antibodies by Weil-Felix test. Therefore it can be concluded that both rapid test and ELISA are equally good. In the high work load centres, ELISA should be used but with less number of samples rapid method may be used for early diagnosis of scrub typhus. 
FIGURE-I

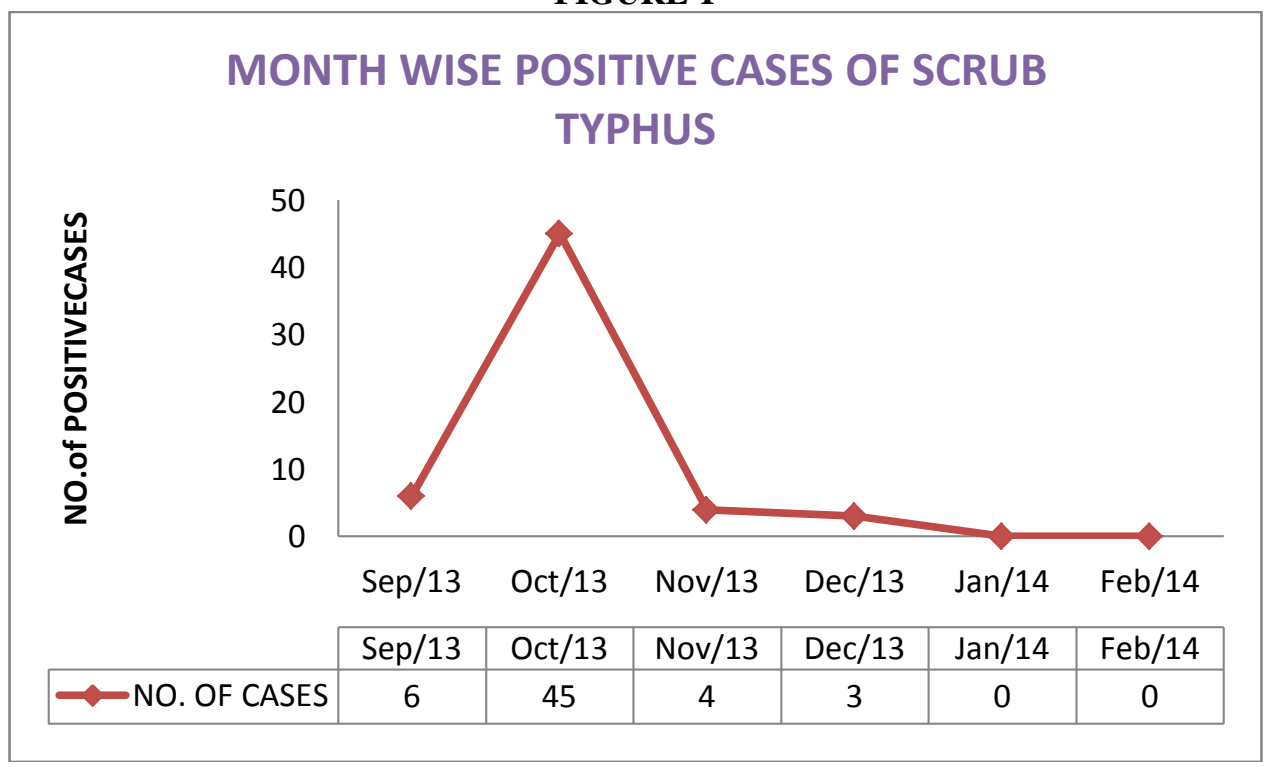

FIGURE - II

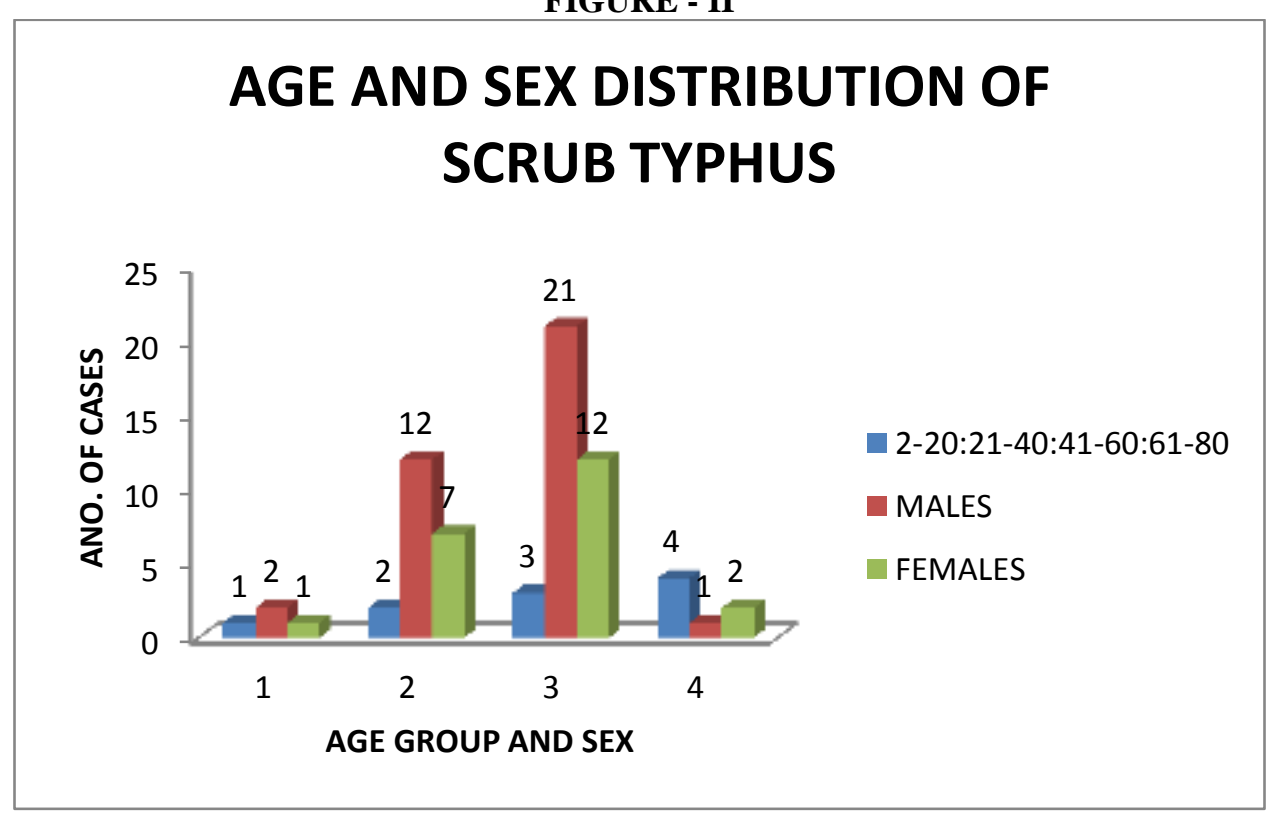


Figure:-Iii Immunochromatography

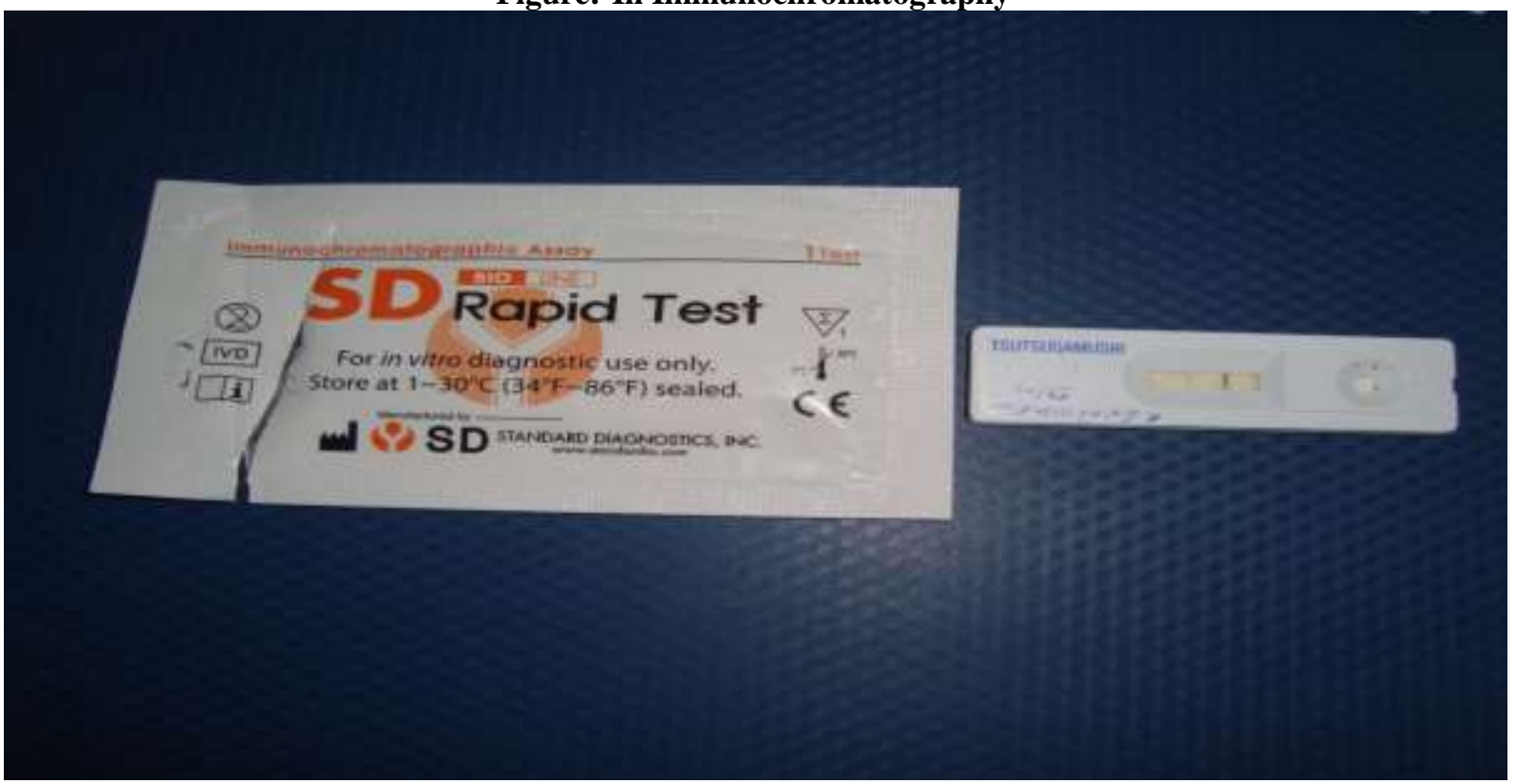

Figure Iv:-Eschar

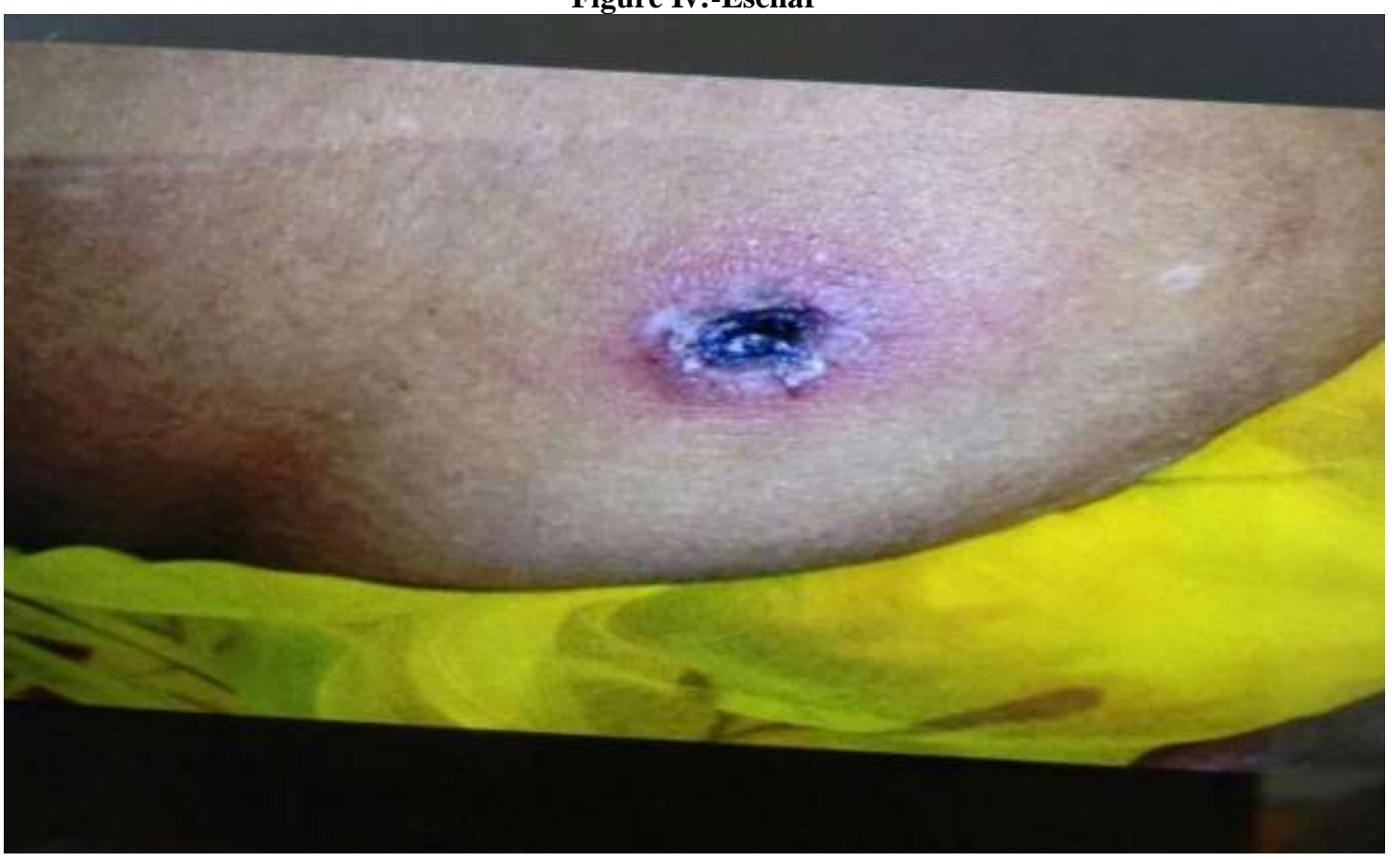

Table-I: Laboratory Tests For Diagnosis Of Scrub Typhus

\begin{tabular}{|l|l|l|l|}
\hline NAME OF THE TEST & POSITIVE & NEGATIVE & TOTAL \\
\hline WEIL-FELIX & 26 & 32 & 58 \\
\hline ICT & 56 & 2 & 58 \\
\hline ELISA & 57 & 1 & 58 \\
\hline WEIL-FELIX \& ICT & 1 & 1 (ELISA) & 2 \\
\hline WEIL-FELIX \& ELISA & 2 & $2(I C T)$ & 4 \\
\hline TOTAL & 142 & 38 & 180 \\
\hline
\end{tabular}

$X^{2}=67.3648, d f=4, p<0.00001$, significant 
Table: Ii Clinical Features

\begin{tabular}{|c|c|c|c|}
\hline Sl. No. & Clinical features & Number of patients & Percentage \\
\hline 1. & $\begin{array}{l}\text { Fever }>38.3^{0} \mathrm{C} \\
>1 \text { week, chills \& rigors }\end{array}$ & 58 & 100 \\
\hline 2. & Headache & 30 & 51.7 \\
\hline 3. & Nausea \&Vomitting & 58 & 100 \\
\hline 4. & Presence of Eschar & 56 & 96.5 \\
\hline 5. & Abdominal pain & 20 & 34.4 \\
\hline 6. & Cough with dyspnea & 15 & 25.8 \\
\hline 7. & Myalgia & $\mathbf{5 0}$ & 86.2 \\
\hline 8. & Hepatosplenomegaly & 26 & 62 \\
\hline 9. & Skin rash & $\mathbf{0 5}$ & 8.6 \\
\hline 10. & Oliguria & 20 & 34.4 \\
\hline 11. & Hypotension & $\mathbf{5 0}$ & 86.2 \\
\hline 12. & Mortality & 01 & 1.7 \\
\hline
\end{tabular}

Table:-Iii Other Laboratory Parameters In Scrub Typhus Cases

\begin{tabular}{|c|c|c|c|}
\hline Sl. No. & Name of the investigation & Number of patients & Percentage \\
\hline 1. & $\begin{array}{l}\text { Total leucocyte count } \\
\text {-less than } 4.3 \times 10^{3} / \mathrm{mm}^{3} \\
\text {-Between } 4.3 \times 10^{3} / \mathrm{mm}^{3} \\
\text {-more than } 4.3 \times 10^{3} / \mathrm{mm}^{3}\end{array}$ & $\begin{array}{l}6 \\
8 \\
44\end{array}$ & $\begin{array}{l}13.4 \\
13.8 \\
75.8\end{array}$ \\
\hline 2. & $\begin{array}{l}\text { Platelet count below } \\
1.4 \text { lakhs } / \mathrm{mm}^{3}\end{array}$ & 48 & 82.7 \\
\hline 3. & $\begin{array}{l}\text { Liver function tests } \\
\text { - Raised SGOT }(>40 \mathrm{u} / \mathrm{L}) \\
\text { - Raised SGPT }(>36 \mathrm{u} / \mathrm{L}) \\
\text { - Raised serum alkaline phosphatase } \\
\text { (>150IU/L) } \\
\text { - Raised total Bilirubin (>1gm/dl) }\end{array}$ & $\begin{array}{l}42 \\
16 \\
32 \\
32\end{array}$ & $\begin{array}{l}72.4 \\
27.6 \\
\\
55.1 \\
44.8\end{array}$ \\
\hline 4. & $\begin{aligned} & \text { Renal function tests } \\
&-\quad \text { Raised blood urea }(>45 \mathrm{mg} / \mathrm{dl}) \\
&- \text { Raised serum creatinine }(>1.5 \mathrm{mg} / \mathrm{dl})\end{aligned}$ & $\begin{array}{l}14 \\
06\end{array}$ & $\begin{array}{l}24.1 \\
13.4\end{array}$ \\
\hline
\end{tabular}

\section{Conclusion:-}

Scrub typhus is prevalent but an under diagnosed disease in India. Scrub typhus cases have been reported from neighbouring states like Tamil Nadu, Pondicherry, Kerala, Karnataka and Orissa. The climatic conditions in Andhra Pradesh are more or less similar to these states. Therefore it is recommended that scrub typhus should be included in the differential diagnosis of Pyrexia of Unknown Origin along with other endemic diseases during cooler months between September and October in this region. Rapid ICT and specific diagnostic methods using ELISA can be carried out timely for early diagnosis of scrub typhus. An early empiric therapy with Doxycycline and Azithromycin can be given to reduce serious complications which are associated with high mortality.

\section{Acknowledgements:-}

We are thankful to all the physicians and department of SPM who extended their help in completing this study.

\section{References:-}

1. Ahmad S, Srivastava S, Verma S.K., Puri P, Shriazi N. scrub typhus in Uttarakhand, India: A common rickettsial disease in an uncommon geographical region. Trop Doct. 2010 July:40(3):188- 90 : doi :10.1258/td 2010.090447.

2. Baily \& Scott diagnostic microbiology $-10^{\text {th }}$ edition. Betty A Forbes Daniel F, Sahm, Alice S. Weiss Field.

3. Biswajyothi Borkatoty, Aniruddha Jakharia, Dipankar Biswas, Jagadish mahanta. Co-infection of scrub typhus and leptospirosis in patients with Pyrexia unknown origin in Longding district of Arunachal Pradesh in 2013. Indian journal of medical microbiology, (2016) 34(1):88-91. 
4. Boorugu H, Dinaker M, Roy ND, Jude JA. Reporting a case of scrub typhus from Andhra Pradesh. J Assoc Physicians India 2010;42:209-13.

5. Chang WH. Current status of Tsutsugamushi disease in Korea. J. Korean Med Sci 1995:10:227-38.

6. Dass R, Deka NM, Guwarah GS, Barman H, Hoque R, Mili D, etal. Characteristics of pediatric scrub typhus during an outbreak in the North Eastern region of India: Peculiarities in clinical presentation, laboratory findings and complications. Indian J Pediatr 2011:78:1365-70.

7. District Laboratory Practice in Tropical Countries South Asian Edition, 2006, Part I by Monika cheesbrough.

8. Jang W, Huh M, Park K, Choi M, Kim IS. Evaluation of immunoglobulin M capture Enzyme linked immunosorbent assay for diagnosis of Orientia tsutsugamushi infection. ClinDiagn Lab Immunol 2003:10:3948.

9. Kammili N, Swathi A, Devara SM, Anuradha PR. Prevalence of scrub typhus among acute undifferentiated febrile illness cases provisionally diagnosed as Dengue fever. J Evol Med Dent Sci 2013;2:2661-64.

10. Kim DM, Won KJ, Park CY, Yu KD, Kim HS, Yang TY, et al. distribution of Eschars on the body of Scrub Typhus patients: A prospective study. Am J Trop Med Hyg 2007;76:806-9.

11. Kim DM, Kim SW, Choi SH, Yun NR. Clinicl and laboratory findings associated with scrub typhus. BMC Infect Dis 2010;10:108.

12. Koh GC, Maude RJ, Paris DH, Newton PN, Blacksell SD. Diagnosis of Scrub typhus. Am J Trop Med Hyg, 2010 Mar;82(3);368-70. Doi:10.4269/ajtmh. 2010.09-0233.

13. Mansons Tropical Diseases by Jeremy Farrar, Peter Hotez, Thomas Junghanss, Gagandeep Kang, David Lalloo, Nicholas White, $23^{\text {rd }}$ edition.

14. Mathai E, Rolain JM, Verghese GM, Abraham OC, Mathai D, Mathai M, et al,. Outbreak of scrub typhus in southern india during the cooler months. Ann NY AcadSci 2003:990:359-64.

15. R Bithu, V Kanodia, RK Maheswari - possibility of Scrub typhus in fever of unknown origin (FUO) cases: An experience from Rajasthan: Indian Journal of Medical Microbiology - (2014) 32(4):387-390.

16. Medical Microbiology: A Guide to Microbial Infections: Pathogenesis, Immunity, Laboratory Diagnosis and Control by David Greenwood, Richard C.B. BLACK, John F. Peutherer, Michael R. Barer. $17^{\text {th }}$ Revised edition.

17. Park's text book of preventive and social medicine by K. Park, $23^{\text {rd }}$ edition 2015.

18. Razak A, Satyanarayanan V, Prabhu M, Sangar M Balasubramanian R. scrub typhus in southern india: are we doing enough? Trop Doct-2010. Jul:40(3):149-51, doi:10.1258/td 2010.090508.

19. S Gurung, J Pradhan, PY Bhutis. Outbreak of scrub typhus in North east Himalayan region-sikkim. An emerging threat. Indian journal of medical microbiology, (2013) 31(1):72-74.

20. Sharma A, Mahajan S, Gupta ML, Kanga A, Sharma V. investigation of an outbreak of scrub typhus in the Himalayan region of India. Jpn J Infect Dis 2005;58:208-10.

21. Tsay RW, Chang FY. Serious complications in scrub typhus. J Microbiol Immunol Infect 1998;31:240-4.

22. Vivekanandan M, Mani A, Priya YS, Singh A, Jayakumar S, Purthy S. outbreak of scrub typhus in Pondicherry: J Associ Physicians India, 2010. Jan:58:24-8. 